Research Paper

\title{
Bone Metastases Pattern in Newly Diagnosed Metastatic Bladder Cancer: A Population-Based Study
}

Chao Zhang ${ }^{*}$, Lele $\mathrm{Liu}^{1 *}$, Fang Tao ${ }^{* *}$, Xu Guo ${ }^{1,6}$, Guowei Feng 3 , Feiran Chen ${ }^{3}$, Yao Xu1 ${ }^{1}$, Lili Li1 ${ }^{1}$, Xiuxin Han ${ }^{1}$, Vladimir P. Baklaushev ${ }^{4}$, Andrey S. Bryukhovetskiy ${ }^{5}$, Xin Wang ${ }^{2 \bowtie}$, Guowen Wang ${ }^{1 凶}$

1. Department of Bone and Soft Tissue Tumors, Tianjin Medical University Cancer Institute and Hospital, National Clinical Research Center for Cancer, Key Laboratory of Cancer Prevention and Therapy, Tianjin's Clinical Research Center for Cancer, Tianjin, China.

2. Department of Epidemiology and Biostatistics, First Affiliated Hospital, Army Medical University, 30 Gaotanyan Street Shapingba District, Chongqing, China.

3. Department of Urology, Tianjin Key Laboratory of Breast Cancer Prevention and Therapy, Ministry of Education, National Clinical Research Center for Cancer, Tianjin Medical University Cancer Institute and Hospital, Tianjin, China.

4. Federal Research and Clinical Center of Specialized Medical Care and Medical Technologies, Federal Biomedical Agency of the Russian Federation, Moscow, Russian Federation.

5. Central Clinical Hospital of the Russian Academy of Science, Moscow, Russian Federation.

6. Department of Orthopedics, Cangzhou Central Hospital, Cangzhou, Hebei, China.

*These authors contributed equally to this work.

$\square$ Corresponding authors: Dr. Xin Wang (wangxinmarine@126.com), address: First Affiliated Hospital, Army Medical University, 30 Gaotanyan Street Shapingba District, Chongqing 400038, China and Dr. Guowen Wang (wangguowen@tmu.edu.cn), address: Tianjin Medical University Cancer Institute and Hospital, Huanhu Xi Road, Tiyuan Bei, Hexi District, Tianjin 300060, China.

(c) Ivyspring International Publisher. This is an open access article distributed under the terms of the Creative Commons Attribution (CC BY-NC) license (https://creativecommons.org/licenses/by-nc/4.0/). See http://ivyspring.com/terms for full terms and conditions.

Received: 2018.07.23; Accepted: 2018.09.06; Published: 2018.11.25

\begin{abstract}
Purpose: Based on a large-population analysis, we aimed to estimate the incidence and survival of bone metastases (BM) in initial bladder cancer (BC) patients and to identify the risk and prognostic factors of $B C$ patients with BM.

Patients and methods: Using the National Cancer Institute's Surveillance, Epidemiology, and End Results (SEER) database, bladder cancer patients diagnosed between 2010 and 2014 were retrieved. Multivariate logistic and Cox regression analyses were employed to identify risk factors and prognostic factors for BM in BC patients. A Kaplan-Meier analysis with log-rank test was used to estimate the overall survival for $B C$ and the difference between the survival curves.

Results: A total of 1,223 (1.39\%) BC patients were diagnosed with de novo BM. Variables such as age between 41 to 60 years, black race, unmarried status, higher $T$ stage, higher $N$ stage, poor tumour differentiation grade, lung metastases, liver metastases, and brain metastases were positively associated with BM occurrence. The median survival for BC patients with BM was dramatically decreased to 4.0 months. Factors including advanced age, absence of surgery, and presence of lung, liver, or brain metastases all predicted worse survival.

Conclusion: BM can dramatically decrease the survival of bladder cancer patients. The findings of the present study can provide population-based identification of risk and prognostic factors for BC patients with BM at initial diagnosis, which can be used for BM occurrence prediction and individualized treatment plan-making.
\end{abstract}

Key words: SEER, bone metastases, risk factor, prognostic factor, bladder cancer

\section{Introduction}

Bladder cancer (BC) is the seventh-most common malignancy and the second-most common urological malignancy in men [1]. It was reported that annually, the number of new BC cases were more than 79,000, and annual death cases led by $\mathrm{BC}$ were more than 16,000 [2]. Patients with metastatic BC generally have 
a poor prognosis, surviving just a few months because of the ease with which it invades the muscle layer [3]. In previous studies, approximately $10-15 \%$ of BC patients were reported to present at diagnosis with metastatic disease [4,5]. Bone metastases (BM) were reported to be correlated with skeletal complications and decrease survival and quality of life in urogenital neoplasms patients [6-8].

It is widely accepted that early diagnosis of $\mathrm{BM}$ from BC could benefit from timely medical intervention and skeletal-related events (SREs) prevention $[4,7]$. Currently, there are no screening guidelines for performance of routine evaluation of $\mathrm{BM}$ in BC patients. Clinically, diagnosis of BM in BC patients mainly relies on bone scan and PET-CT scanning. However, considering the high cost burden of these tests, neither bone scan nor PET-CT can be used as routine screening strategies. Additionally, it was reported that tumour markers in BC are not

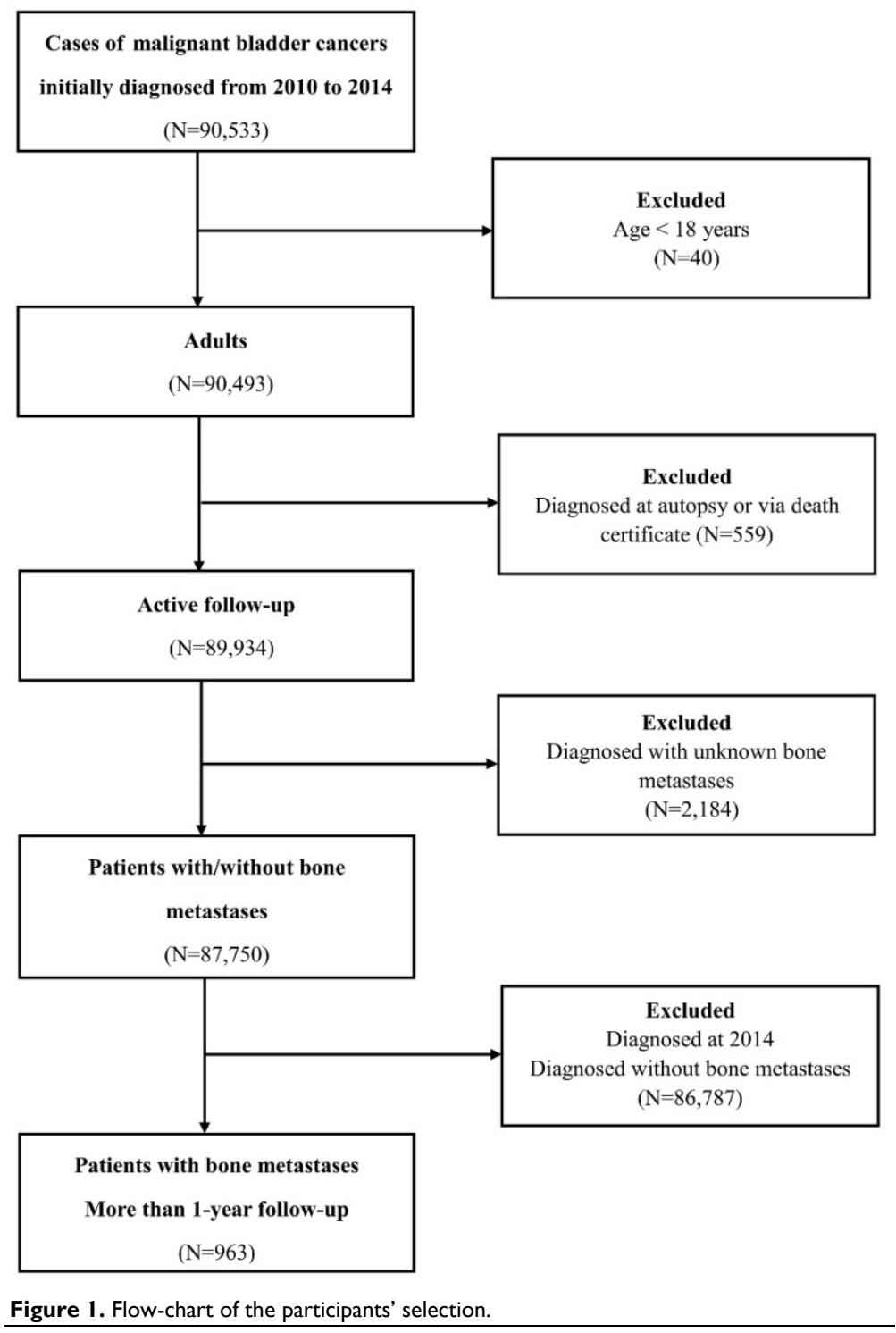

sensitive enough to predict BM [9]. Thus, studies looking into risk factors for BM in BC are warranted.

A new study based on 902 patients with BC suggested the incidence of BM is 5.5\% [5]. That study also concluded that concentrations of alkaline phosphatase (ALP) $>116 \mathrm{U} / \mathrm{L}, \mathrm{HB}<37.5 \mathrm{~g} / \mathrm{L}$ and calcium $>2.54 \mathrm{mmol} / \mathrm{L}$ were the main risk factors that led patients with BC to develop BM [5]. However, to build an accurate and portable BM-preventive system for $\mathrm{BC}$, knowledge of additional common clinical risk factors was needed. Accordingly, to further summarize the epidemiological characteristics and prognosis of metastatic $\mathrm{BC}$ and to find more risk factors for BM, the present study was performed.

National Cancer Institute's Surveillance, Epidemiology, and End Results (SEER) is an open access database that provides cancer incidence and survival data from 18 established cancer registries across the United States, comprising approximately $30 \%$ of the total US population. SEER cohort is a widely used database, with complete demographic and clinical data and long-term, high quality follow-up for assessing cancer epidemiological characteristics around the world.

The SEER database was employed in the present study. The incidence and risk factors for BM with initial BC were analysed. Meanwhile, for $\mathrm{BC}$ patients presenting with $\mathrm{BM}$ at diagnosis, survival estimates and prognostic factors were summarized.

\section{Methods}

Patients diagnosed with bladder cancer were selected from the SEER programme between 2010 and 2014, because sites of metastases were not collected until 2010. The datasets generated and/or analysed during the current study are available in the SEER database. (Information Management Service, Inc. Calverton, MD, USA, https://seer. cancer.gov/data/). Data on the primary site labelled "bladder cancer (C67.0-67.9)" was identified. The exclusion criteria were as follows: patients $<18$ years old (adult's patients); diagnosed with carcinoma in situ and benign; diagnosed at autopsy or via death certificate; unknown BM or follow-up. To identify BM risk factors, 87,750 patients within the SEER database diagnosed with BC with definite details about BM from January 1, 2010, to December 31, 2014, were selected. Among those, for survival analysis, 963 BC patients with BM who were initially diagnosed between 2010 and 2013 were retrieved. (Figure 1) 


\section{Ethnics Statement}

The SEER database is an open public database, and the release of data from the SEER database does not require informed patient consent because cancer is a reportable disease in every state of the United States. The present study complied with the 1964 Helsinki Declaration and its later amendments or comparable ethical standards.

\section{Statistical analysis}

To determine the risk factors for developing BM at diagnosis, univariate and multivariate logistic regression were performed. Patients' clinical data were collected: age $(\leq 40,41-60,61-80$ and $\geq 81$ years $)$, sex (female and male), race [white, black, AI (American Indian/Alaska Native), and API (Asian or Pacific Islander)], marital status (married and unmarried), insurance status (insured and uninsured), primary tumor $(\mathrm{T})$ stage $(\mathrm{T} 1, \mathrm{~T} 2, \mathrm{~T} 3$, and $\mathrm{T} 4)$, regional lymph node stage (N0, N1, N2 and N3), tumor differentiation grade (grade I, grade II, grade III, and grade IV), the presence or absence of lung metastases, liver metastases, or brain metastases. The primary goal of the survival analysis was to determine overall survival, defined as the time from diagnosis of $\mathrm{BC}$ to all causes of death. Survival rate was calculated using the Kaplan-Meier method, and the difference between survival curves was tested by log-rank test. At the same time, based on these factors, combined with the factor of surgical treatment of primary site (none or yes), a multivariable Cox proportional hazards regression was utilized to investigate the associations with overall survival among BC patients with BM.

All the data were obtained using SEER ${ }^{*}$ Stat Software version 8.3.5. All statistical analyses were performed using SPSS 23.0 (IBM Corporation, Armonk, NY), and all charts of survival were prepared by MedCalc 15.2.2. Two-sided $P$ values less than 0.05 were considered as statistically significant.

\section{Results}

\section{Incidence of bone metastases}

Based on the setting criteria, a total of 87,750 eligible patients were diagnosed with $\mathrm{BC}$ between 2010 and 2014; BM was found in 1.39\% $(1,223 / 87,750)$ of the entire cohort at initial diagnosis. In the cohort, 963 BC patients with BM were followed up for more than 1 year. (Table 1 )

\section{Risk factors for developing bone metastases}

Univariate analysis showed that factors significantly associated with $\mathrm{BM}$ occurrence included: older age (OR=0.86, 95\% CI: $0.80-0.94, P<0.001)$, race $(\mathrm{OR}=1.15,95 \% \mathrm{CI}: 1.06-1.24, P<0.001)$, marital status
(OR=0.61, 95\% CI: 0.55-0.69, $P<0.001)$, insured status (OR=0.48, 95\% CI: $0.35-0.66, P<0.001)$, higher primary tumor $(\mathrm{T})$ stage $(\mathrm{OR}=2.68,95 \% \mathrm{CI}$ : 2.55-2.83, $P<0.001)$, higher regional lymph node $(\mathrm{N})$ stage $(\mathrm{OR}=3.24,95 \%$ CI: 3.04-3.45, $P<0.001)$, poor tumor differentiated grade $(\mathrm{OR}=2.09,95 \% \mathrm{CI}: 1.92-2.28, P<0.001)$, the presence of lung metastases $(\mathrm{OR}=44.51,95 \% \mathrm{CI}$ : 38.47-51.49, $P<0.001)$, liver metastases $(\mathrm{OR}=51.11,95 \%$ CI: $43.51-60.03, \quad P<0.001)$, or brain metastases (OR=53.68, 95\% CI: 35.83-80.41, $P<0.001$ ).

As shown in Table 1, multivariate logistic regression suggested that factors significantly associated with BM at initial diagnosis included: age between 41 to 60 years (OR=0.87, 95\% CI: 0.77-0.98, $P=0.03)$, black race $(\mathrm{OR}=1.12$, 95\% $\mathrm{CI}: 1.00-1.26$, $P=0.046)$, unmarried status $(\mathrm{OR}=0.83, \quad 95 \% \mathrm{CI}$ : $0.70-0.98, P=0.03)$, higher $\mathrm{T}$ stage $(\mathrm{OR}=1.66,95 \% \mathrm{CI}$ : $1.53-1.81, P<0.001)$, higher $\mathrm{N}$ stage $(\mathrm{OR}=1.62,95 \% \mathrm{CI}$ : $1.47-1.79, P<0.001)$, poor tumor differentiated grade $(\mathrm{OR}=1.72,95 \%$ CI: 1.53-1.93, $P<0.001)$, and the presence of lung metastases $(\mathrm{OR}=9.87,95 \% \mathrm{CI}$ : 7.71-12.63, $P<0.001)$, liver metastases $(\mathrm{OR}=10.63,95 \%$ CI: 7.98-14.17, $P<0.001)$, or brain metastases $(\mathrm{OR}=7.73$, 95\% CI: 3.45-17.31, $P<0.001)$.

\section{Survival and prognostic factors for BM}

Once BC patients were diagnosed with BM, their survival rates were dramatically decreased. The overall 1-year survival of the cohort was $84 \%$ but it was only $21 \%$ among patients with BM. The median overall survival time for $963 \mathrm{BC}$ patients with BM was only 4 months (95\% CI: 3.55-4.45 months, Figure 2A), and $915(95.02 \%)$ patients died at the end of follow-up. In the univariate analysis model, factors including older age (Figure 2B), American Indian/Alaska Native race (Figure 2C), and the presence of lung metastases (Figure 2D), liver metastases (Figure 2E), or brain metastases (Figure 2F) were negatively associated with overall survival. Conversely, surgical treatment of the primary site was found to be positively associated with overall survival rate $(P<0.001$, Figure 2G).

In the multivariate stepwise Cox regression model (Table 2), elder (HR=1.31, 95\% CI: 1.18-1.45, $P<0.001)$, the presence of lung metastases $(\mathrm{HR}=1.19$, 95\% CI: $1.02-1.40, P=0.03)$, liver metastases $(H R=1.53$, 95\% CI: $1.30-1.81, P<0.001)$, or brain metastases (HR=1.47, 95\% CI: 1.04-2.09, $P=0.03$ ) were negatively associated with overall survival; however, surgery was positively associated with overall survival (HR=0.83, 95\% CI: 0.77-0.89, $P<0.001$ ).

\section{Discussion}

It was reported that approximately $5 \%$ of the BC patients presented initially with metastatic disease, 
with bone being the second-most affected organ and it was reported to occur in $30 \%$ to $40 \%$ patients with metastatic BC $[10,11]$. With the largest population known to date, this study looked into the incidence of $\mathrm{BC}$ patients with $\mathrm{BM}$ at diagnosis and showed $1.39 \%$ of the entire $\mathrm{BC}$ cohort was identified with $\mathrm{BM}$ at diagnosis.

Table 1. Multivariate logistic regression for analysing demographic and related clinical characteristics for developing Bone Metastases in patients with initial bladder cancer (diagnosed 2010-2014).

\begin{tabular}{|c|c|c|c|c|c|}
\hline \multirow{2}{*}{$\begin{array}{l}\text { Subject } \\
\text { characteristics }\end{array}$} & \multicolumn{3}{|c|}{ Patients' No. of BC (2010-2014) } & \multirow[t]{2}{*}{ OR $(95 \% \mathrm{CI})$} & \multirow[t]{2}{*}{ P-value } \\
\hline & $\begin{array}{l}\text { With Bone } \\
\text { Metastases }\end{array}$ & $\begin{array}{l}\text { Entire } \\
\text { Cohort, N }\end{array}$ & $\begin{array}{l}\text { Incidence } \\
(\%)\end{array}$ & & \\
\hline Age, in years & & & & $0.87(0.77-0.98)$ & 0.03 \\
\hline$\leq 40$ & 10 & 890 & 1.12 & 1(Reference) & 1.00 \\
\hline $41-60$ & 257 & 14533 & 1.77 & $1.93(0.58-6.40)$ & 0.28 \\
\hline $60-80$ & 677 & 49908 & 1.36 & $1.51(0.46-4.97)$ & 0.50 \\
\hline$\geq 81$ & 279 & 22419 & 1.24 & $1.25(0.38-4.17)$ & 0.71 \\
\hline Race & & & & $1.12(1.00-1.26)$ & 0.046 \\
\hline White & 1036 & 77512 & 1.34 & 1(Reference) & 1.00 \\
\hline Black & 121 & 5124 & 2.36 & $1.55(1.18-2.02)$ & 0.001 \\
\hline AI & 7 & 280 & 2.5 & $0.78(0.22-2.78)$ & 0.70 \\
\hline API & 58 & 3540 & 1.64 & $1.25(0.83-1.86)$ & 0.29 \\
\hline Unknown & 1 & 1294 & 0.08 & NA & NA \\
\hline \multicolumn{6}{|l|}{ Marital Status } \\
\hline Unmarried & 569 & 29594 & 1.92 & 1(Reference) & 1.00 \\
\hline Married & 598 & 50544 & 1.18 & $0.83(0.70-0.98)$ & 0.03 \\
\hline Unknown & 56 & 7612 & 0.74 & NA & NA \\
\hline \multicolumn{6}{|l|}{$\begin{array}{l}\text { Insurance } \\
\text { Status }\end{array}$} \\
\hline Insured & 1181 & 86249 & 1.37 & 1(Reference) & 1.00 \\
\hline Uninsured & 42 & 1501 & 2.79 & $1.20(0.67-2.17)$ & 0.54 \\
\hline T Stage & & & & $1.66(1.53-1.81)$ & $<0.001$ \\
\hline $\mathrm{T} 1$ & 187 & 66564 & 0.28 & 1(Reference) & 1.00 \\
\hline $\mathrm{T} 2$ & 457 & 12627 & 3.62 & $5.56(4.40-7.01)$ & $<0.001$ \\
\hline T3 & 90 & 3499 & 2.57 & $2.58(1.81-3.66)$ & $<0.001$ \\
\hline $\mathrm{T} 4$ & 209 & 2902 & 7.20 & 6.31(4.69-8.50) & $<0.001$ \\
\hline Unknown & 280 & 2158 & 12.97 & NA & NA \\
\hline N Stage & & & & $1.62(1.47-1.79)$ & $<0.001$ \\
\hline No & 663 & 82425 & 0.81 & 1(Reference) & 1.00 \\
\hline N1 & 101 & 1451 & 6.96 & $1.64(1.19-2.28)$ & 0.003 \\
\hline $\mathrm{N} 2$ & 190 & 1840 & 10.33 & $2.85(2.22-3.66)$ & $<0.001$ \\
\hline N3 & 56 & 436 & 12.84 & $4.38(2.97-6.46)$ & $<0.001$ \\
\hline Unknown & 213 & 1598 & 13.33 & NA & NA \\
\hline Grade & & & & $1.72(1.53-1.93)$ & $<0.001$ \\
\hline I & 11 & 9687 & 0.11 & 1(Reference) & 1.00 \\
\hline II & 38 & 15262 & 0.25 & $1.54(0.69-3.45)$ & 0.30 \\
\hline III & 261 & 12531 & 2.08 & $4.71(2.27-9.78)$ & $<0.001$ \\
\hline IV & 544 & 27124 & 2.01 & $4.95(2.41-10.16)$ & $<0.001$ \\
\hline Unknown & 369 & 23146 & 1.59 & NA & NA \\
\hline \multicolumn{6}{|l|}{ Lung Met } \\
\hline None & 846 & 86551 & 0.98 & 1(Reference) & 1.00 \\
\hline Yes & 332 & 1086 & 30.57 & $9.87(7.71-12.63)$ & $<0.001$ \\
\hline Unknown & 45 & 113 & 39.82 & NA & NA \\
\hline \multicolumn{6}{|l|}{ Liver Met } \\
\hline None & 917 & 86912 & 1.06 & 1(Reference) & 1.00 \\
\hline Yes & 274 & 776 & 35.31 & $10.63(7.98-14.17)$ & $<0.001$ \\
\hline Unknown & 32 & 62 & 51.61 & NA & NA \\
\hline \multicolumn{6}{|l|}{ Brain Met } \\
\hline None & 1139 & 87590 & 1.30 & 1(Reference) & 1.00 \\
\hline Yes & 41 & 99 & 41.41 & $7.73(3.45-17.31)$ & $<0.001$ \\
\hline Unknown & 43 & 61 & 70.49 & NA & NA \\
\hline
\end{tabular}

Table 2. Multivariable Cox Regression for analysing prognostic factors for primary bladder cancer with bone metastases (diagnosed 2010-2013).

\begin{tabular}{|c|c|c|c|c|c|}
\hline \multirow[t]{2}{*}{$\begin{array}{l}\text { Subject } \\
\text { characteristics }\end{array}$} & \multicolumn{2}{|c|}{$\begin{array}{l}\text { Patients' No. of } \\
\text { BC with BM }\end{array}$} & \multirow{2}{*}{$\begin{array}{l}\text { Survival, } \\
\text { Median ( } 95 \% \\
\text { CI), mo }\end{array}$} & \multirow[t]{2}{*}{ HR (95\% CI) } & \multirow[t]{2}{*}{ P-Value } \\
\hline & Overall & Dead (N, \%) & & & \\
\hline Age, in years & & & & 1.31(1.18-1.45) & $<0.001$ \\
\hline$\leq 40$ & 8 & $8(100.00)$ & $4(0.00-8.16)$ & 1(Reference) & 1.00 \\
\hline $41-60$ & 201 & $186(92.54)$ & $5(3.74-6.26)$ & $0.83(0.40-1.69)$ & 0.60 \\
\hline $61-80$ & 537 & $505(94.04)$ & $4(3.36-4.64)$ & $0.97(0.48-1.97)$ & 0.94 \\
\hline$\geq 81$ & 217 & 216(99.54) & $2(1.50-2.50)$ & $1.46(0.71-2.98)$ & 0.30 \\
\hline Race & & & & $1.08(0.98-1.18)$ & 0.13 \\
\hline White & 817 & $776(94.98)$ & $4(3.50-4.50)$ & 1(Reference) & 1.00 \\
\hline Black & 95 & $90(94.74)$ & $4(3.18-4.82)$ & $1.09(0.87-1.37)$ & 0.44 \\
\hline $\mathrm{AI}$ & 6 & $6(100.00)$ & $0(\mathrm{NR})$ & $3.50(1.45-8.49)$ & 0.01 \\
\hline API & 45 & 43(95.56) & $3(0.62-5.39)$ & $1.20(0.88-1.64)$ & 0.25 \\
\hline \multicolumn{6}{|l|}{ Lung Met } \\
\hline None & 670 & $633(94.48)$ & $4(3.46-4.54)$ & 1(Reference) & 1.00 \\
\hline Yes & 257 & $248(96.50)$ & $3(2.47-3.53)$ & $1.19(1.02-1.40)$ & 0.03 \\
\hline Unknown & 36 & $34(94.44)$ & NR & NA & NA \\
\hline \multicolumn{6}{|l|}{ Liver Met } \\
\hline None & 721 & $678(94.04)$ & $4(3.51-4.49)$ & 1(Reference) & 1.00 \\
\hline Yes & 218 & 214(98.17) & $2(1.54-2.46)$ & $1.53(1.30-1.81)$ & $<0.001$ \\
\hline Unknown & 24 & 23(95.83) & NR & NA & NA \\
\hline \multicolumn{6}{|l|}{ Brain Met } \\
\hline None & 893 & 847(94.85) & $4(3.54-4.46)$ & 1(Reference) & 1.00 \\
\hline Yes & 34 & $34(100.00)$ & $2(1.47-2.54)$ & $1.47(1.04-2.09)$ & 0.03 \\
\hline Unknown & 36 & $34(94.44)$ & NR & NA & NA \\
\hline \multicolumn{6}{|l|}{ Surg(pri) } \\
\hline None & 303 & 296(97.69) & $2(1.46-2.54)$ & 1(Reference) & 1.00 \\
\hline Yes & 658 & 617(93.77) & $5(4.37-5.63)$ & $0.83(0.77-0.89)$ & $<0.001$ \\
\hline Unknown & 2 & $2(100)$ & NR & NA & NA \\
\hline
\end{tabular}

Abbreviations: $\mathrm{BC}$, bladder cancer; $\mathrm{BM}$, bone metastases; $\mathrm{AI}$, American

Indian/Alaska Native; API, Asian or Pacific Islander; Met, metastases; Surg(pri), surgical treatments of primary site; NR, not reached; NA, not available; HR, hazard ratio; CI, confident interval. All factors with Unknown Data were removed from multivariable Cox regression model and Kaplan-Meier analysis.

The identification of the risk factors for $\mathrm{BM}$ development in $\mathrm{BC}$ patients makes it possible to guide physicians in the management of the high-risk patient of developing metastasis, increase the quality of life and decrease skeletal related events. Based on our risk factors analysis, we determined that BC patients are likely being diagnosed with BM, when they present with a series of factors, including age between 41 to 60 years, black race, unmarried marital status, higher $\mathrm{T}$ stage, higher $\mathrm{N}$ stage, poor tumor grade, and the presence of lung, liver, and brain metastases, which was in line with other urinary system cancers [12-14]. Accordingly, the examinations such as bone scan may be considered as an optional method for the patients with the aforementioned factors for BM development.

Additionally, black race was proved to be one of the risk factors for $\mathrm{BM}$ at diagnosis, which was consistent with other reported cancer types $[13,15,16]$. Previous studies also reported black patients showed higher-stage disease and worse disease-specific survival compared with white patients $[17,18]$. Further studies looking into the potential explanations for black patients' poor survival in metastatic tumor and the access to care, quality of care and 
treatment plans for black $\mathrm{BC}$ patients with $\mathrm{BM}$ is warranted.

In the present study, BC patients who presented with $\mathrm{BM}$ at diagnosis showed a marked decrease in survival rates compared with $B C$ patients without $B M$ occurrence, the median OS for the BM cohort was only 4 months. In the previous study, the 5-year cancer-specific survival following a diagnosis of metastatic BC was reported to be only 8\% [19]. Our results further proved the poor survival of $B C$ patients with $\mathrm{BM}$ at diagnosis. The latest study suggested that among the three most common genitourinary neoplasms, compared with median survival times for patients with $\mathrm{BM}$ in prostate cancer (210 days) and kidney cancer (182 days), survival for bladder cancer (68 days) was the worst [20]. Based on our prognostic factors analysis, we clarified that $B C$ patients with $B M$ at diagnosis were associated with a significantly higher risk of mortality when they presented with a series of factors, including advanced age, absence of surgery, and presence of lung metastases, liver metastases, and brain metastases. The effect of metastatic sites on patients' prognosis among several neoplasms was studied [21,22]. Liver metastases, bone metastases, and brain metastases have been proven to be independent unfavourable prognostic factors for BC patients [23].

To our knowledge, our study is the first to analyse prognostic factors for BC patients with BM. Physicians should pay more attention to their patients' presentation with the revealed factors. Early supportive treatment and intimate observation should be considered for these patients. Targeted treatment strategies and medical care should be paid on the BC patients with high risk factors for death, to prolong the survival time and implement the tertiary prevention. Further research should be performed to find more prognostic factors to build an accurate predictive system for $\mathrm{BC}$ patients with $\mathrm{BM}$.
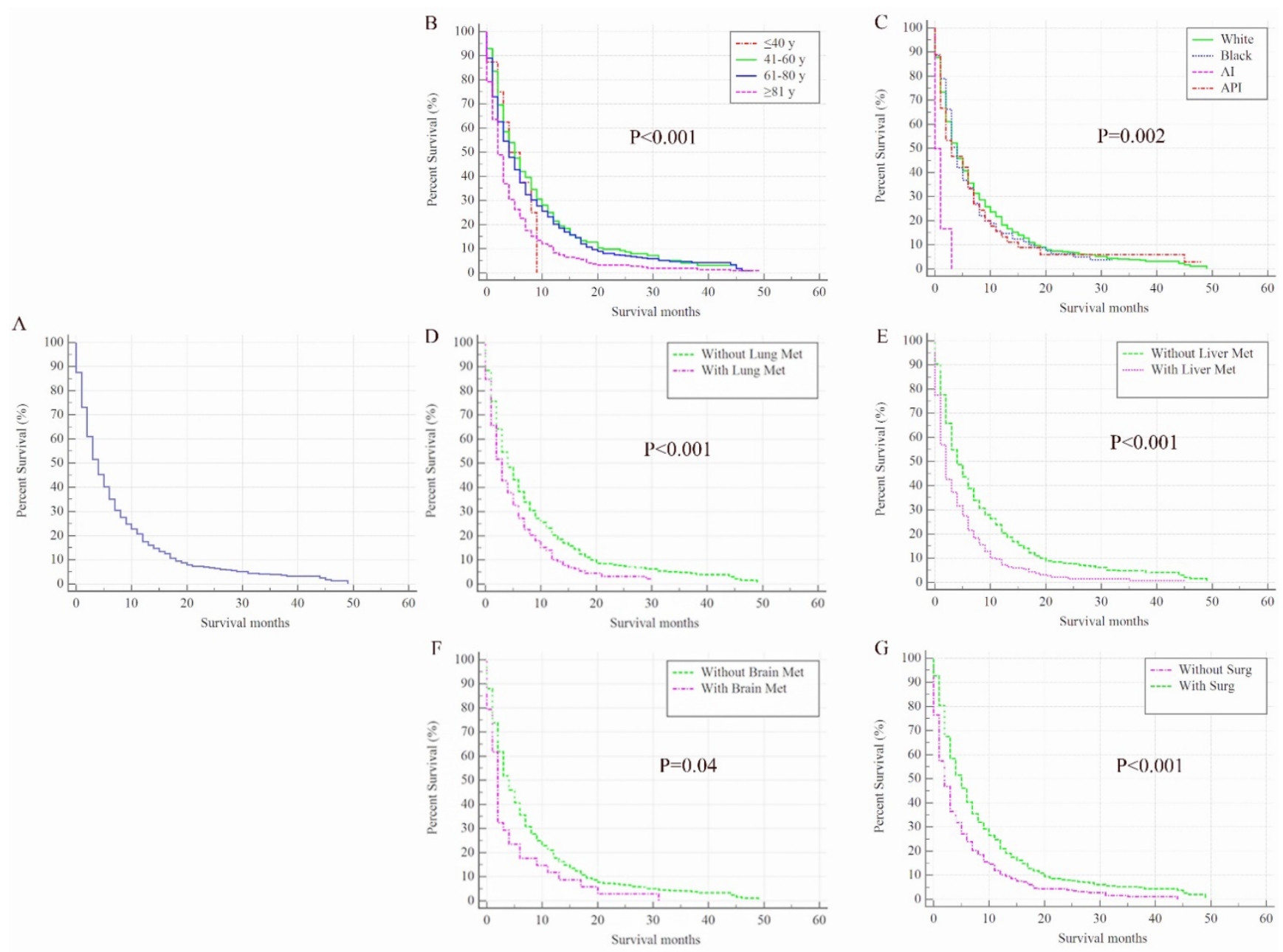

Figure 2. Kaplan-Meier analysis of overall survival among patients diagnosed with initial bladder cancer with bone metastases (A, overall), stratified by age (B), race (C), presence of lung metastases (D), liver metastases (E), brain metastases (F) and surgical treatments of the primary site (G). Al, American Indian/Alaska Native; API, Asian or Pacific Islander; Met, metastases; Surg, surgical treatments of primary site. 
The major limitation of the present study came from the SEER database itself, as the real BM rate in BC patients might be underestimated for nonrecording in asymptomatic cases. In addition, information on skeletal-related events, thought to be one of the most important prognostic factors in urologic malignancies, were not available. Additionally, the present study was performed based on the SEER cohort and the results were not validated by external dataset. More related studies were needed to further confirm the results in the future to validate the extrapolation of results.

The incidence of $\mathrm{BM}$ in newly diagnosed $\mathrm{BC}$ patients was approximately $1.39 \%$. BM dramatically decreased the survival of $\mathrm{BC}$ patients. Bone scan should be considered a routine examination for $B C$ patients of black race at initial diagnosis. The risk and prognostic factors for BC patients with BM identified herein may provide the basis for early detection of $\mathrm{BM}$ in $\mathrm{BC}$ patients, and guide clinicians to choose targeted treatment options to promote their survival.

\section{Acknowledgments}

The Authors would like to thank SEER public database to make the bladder cancer patients data available. We would also thank Chong Zhang, Tingwei Zhu, Jincai Duan, Dengming Yan, Fuli Li, Yile Lin, Shuwei Ma, Shijia Zhu, Qingya Zhong, Xinrui Yang, and Xuehang Ge for their contribution on data collection.

The present study was sponsored by Natural Science Foundation of China (81702161, 81872184, 81602363), Russian Foundation of Basic Research (15-29-01338), Natural Science Foundation of Tianjin Science and Technology Committee China (17JCQNJ C11000), Natural Science Foundation of Tianjin Medical University (2016KYZQ10), China Postdoctoral Science Foundation Grant (2017M621091), and The Doctor Start-up Grant of Tianjin Medical University Cancer Institute and Hospital (B1612, B1711).

\section{Competing Interests}

The authors have declared that no competing interest exists.

\section{References}

1. Siegel RL, Miller KD, Jemal A. Cancer statistics, 2016. CA Cancer J Clin. 2016;66(1):7-30.

2. Dong F, Xu T, Shen Y, Zhong S, Chen S, Ding Q, et al. Dysregulation of miRNAs in bladder cancer: altered expression with aberrant biogenesis procedure. Oncotarget. 2017;8(16):27547-27568.

3. Matos J, Mussetto I, Podestà R, Schettini D, Gandolfo N. Bladder cancer presenting with acrometastases: a different cause of foot pain. Skeletal Radiol. 2018. [Epub ahead of print]

4. Dong F, Shen Y, Gao F, Xu T, Wang X, Zhang X, et al. Prognostic value of site-specific metastases and therapeutic roles of surgery for patients with metastatic bladder cancer: a population-based study. Cancer Manag Res. 2017;9:611-626.
5. Huang P, Lan M, Peng AF, Yu QF, Chen WZ, Liu ZL, et al. Serum calcium, alkaline phosphotase and hemoglobin as risk factors for bone metastases in bladder cancer. PLoS One. 2017;12(9):e0183835.

6. Guo Q, Zhang C, Guo X, Tao F, Xu Y, Feng G, et al. Incidence of bone metastasis and factors contributing to its development and prognosis in newly diagnosed renal cell carcinoma: a population-based study. Cancer Manag Res. 2018;10:2935-2944.

7. Guo X, Zhang C, Guo Q, Xu Y, Feng G, Li L, et al. The homogeneous and heterogeneous risk factors for the morbidity and prognosis of bone metastasis in patients with prostate cancer. Cancer Manag Res. 2018;10:1639-1646.

8. Zhang Y, Guo X, Wang G, Ma W, Liu R, Han X, et al. Real-World Study of the Incidence, Risk Factors, and Prognostic Factors Associated with Bone Metastases in Women with Uterine Cervical Cancer Using Surveillance, Epidemiology, and End Results (SEER) Data Analysis. Med Sci Monit. 2018;24:6387-6397.

9. Froehner M, Hölscher T, Hakenberg OW, Wirth MP. Treatment of bone metastases in urologic malignancies. Urol Int. 2014;93(3):249-256.

10. Witjes JA, Compérat E, Cowan NC, De Santis M, Gakis G, Lebret T, et al. Guidelines on muscle invasive and metastatic bladder cancer. Eur Urol. 2014;65(4):778-779.

11. Shinagare AB, Ramaiya NH, Jagannathan JP, Fennessy FM, Taplin ME, Van den Abbeele AD. Metastatic pattern of bladder cancer: correlation with the characteristics of the primary tumor. AJR Am J Roentgenol. 2011;196(1):117-122.

12. Rodríguez-Antolín A, Gómez-Veiga F, Alvarez-Osorio JK, Carballido-Rodriguez J, Palou-Redorta J, Solsona-Narbón E, et al. Factors that predict the development of bone metastases due to prostate cancer: Recommendations for follow-up and therapeutic options. Actas Urol Esp. 2014;38(4):263-290.

13. Luo D, Liu $\mathrm{Q}, \mathrm{Yu}$ W, Ma Y, Zhu J, Lian $\mathrm{P}$, et al. The homogeneous and heterogeneous risk factors for the morbidity and prognosis of bone metastasis in patients with prostate cancer. Cancer Manag Res. 2018;10:1639-1646.

14. Briganti A, Suardi N, Gallina A, Abdollah F, Novara G, Ficarra V, et al. Predicting the risk of bone metastasis in prostate cancer. Cancer Treat Rev. 2014;40(1):3-11.

15. Sun M, Abdollah F, Liberman D, Abdo A, Thuret R, Tian Z, et al. Racial disparities and socioeconomic status in men diagnosed with testicular germ cell tumors: a survival analysis. Cancer. 2011;117(18):4277-4285.

16. Roetzheim RG, Pal N, Tennant C, Voti L, Ayanian JZ, Schwabe A, et al. Effects of health insurance and race on early detection of cancer. J Natl Cancer Ins. 1999;91(16):1409-1415.

17. Martin AM, Cagney DN, Catalano PJ, Warren LE, Bellon JR, Punglia RS, et al. Brain Metastases in Newly Diagnosed Breast Cancer: A Population-Based Study. JAMA Oncol. 2017;3(8):1069-1077.

18. Yee DS, Ishill NM, Lowrance WT, Herr HW, Elkin EB. Ethnic differences in bladder cancer survival. Urology. 2011;78(3):544-549.

19. Abdollah F, Gandaglia G, Thuret R, Schmitges J, Tian Z, Jeldres C, et al. Incidence, survival and mortality rates of stage-specific bladder cancer in United States: a trend analysis. Cancer Epidemiol. 2013;37(3):219-225.

20. Svensson E, Christiansen CF, Ulrichsen SP, Rørth MR, Sørensen HT. Survival after bone metastasis by primary cancer type: a Danish population-based cohort study. BMJ Open. 2017;7(9):e016022.

21. Wu SG, Li H, Tang LY, Sun JY, Zhang WW, Li FY, et al. The effect of distant metastases sites on survival in de novo stage-IV breast cancer: A SEER database analysis. Tumour Biol. 2017;39(6):1010428317705082.

22. Oweira H, Petrausch U, Helbling D, Schmidt J, Mannhart M, Mehrabi A, et al. Prognostic value of site-specific metastases in pancreatic adenocarcinoma: A Surveillance Epidemiology and End Results database analysis. World J Gastroenterol. 2017; 23(10):1872-1880.

23. Bellmunt J, Choueiri TK, Fougeray R, Schutz FA, Salhi Y, Winquist E, et al. Prognostic factors in patients with advanced transitional cell carcinoma of the urothelial tract experiencing treatment failure with platinum-containing regimens. J Clin Oncol. 2010;28(11):1850-1855. 